\title{
Atmospheric Oxidation of Piperazine Initiated by OH: A Theoretical Kinetics Investigation
}

\author{
Zhonghua Ren, Gabriel da Silva* \\ Department of Chemical Engineering, The University of Melbourne, Parkville 3010, Australia. \\ *E-mail: gdasilva@unimelb.edu.au. Phone: +61 383446627.
}

\begin{abstract}
Piperazine $(\mathrm{Pz})$ mixed with other amines is a proposed carbon capture solvent, but there is concern about the impact of $\mathrm{Pz}$ on air quality, including the potential to produce toxic products. Here, the ${ }^{\circ} \mathrm{OH}$ initiated oxidation of Pz has been studied by $a b$ initio modelling and RRKM / master equation kinetic simulations. The $\mathrm{Pz}+{ }^{\circ} \mathrm{OH}$ reaction is found to proceed at around the capture rate, consistent with experiment, with abstraction predominantly from $\mathrm{C}-\mathrm{H}$ sites, forming an alkyl radical $(\mathrm{PzC})$. The subsequent reaction kinetics of carbon centred $\mathrm{Pz}$ radicals with $\mathrm{O}_{2}$ are also studied, so as to determine the first-generation oxidation products. We find that the $\mathrm{PzC}$ radical predominantly reacts with $\mathrm{O}_{2}$ to produce a cyclic imine product $+\mathrm{HO}_{2}{ }^{\circ}$ under tropospheric conditions, with the stabilized peroxyl radical formed as a minor product. Subsequent reaction of the peroxyl radical with NO produces an alkoxyl radical that can react with $\mathrm{O}_{2}$ to yield a cyclic amide or undergo unimolecular ring opening followed by a second $\mathrm{O}_{2}$ addition $/ \mathrm{HO}_{2}{ }^{\cdot}$ elimination step to produce $\mathrm{CH}_{2}=\mathrm{NCH}_{2} \mathrm{CH}_{2} \mathrm{NHCHO}$.
\end{abstract}

\section{KEYWORDS}

Atmospheric chemistry, kinetics, piperazine, transition state theory, computational chemistry

\section{Introduction}

Carbon capture technology is being actively pursued as a means of reducing $\mathrm{CO}_{2}$ emissions from fossil fuel burning. ${ }^{1-6}$ Among these technologies, absorption into liquid amine solvents is currently the most mature. ${ }^{7-10}$ The amine piperazine $(\mathrm{Pz})$ is one potentially attractive solvent when mixed with other compounds. ${ }^{71-15}$ It is inevitable that significant quantities of volatile amines will be released to the atmosphere during their manufacture, transport, and use in any amine-based carbon capture process, ${ }^{16-19}$ and we therefore require a thorough understanding of the atmospheric chemistry of piperazine.

$\mathrm{Pz}$ is a nitrogen-containing heterocycle with a six-member ring and two secondary amino groups. When released into the atmosphere, $\mathrm{Pz}$ is expected to react predominantly with the ${ }^{\circ} \mathrm{OH}$ radical, ${ }^{20,21}$ via abstraction from $\mathrm{C}-\mathrm{H}$ sites to form an alkyl radical $(\mathrm{PzC})$ or from $\mathrm{N}-\mathrm{H}$ sites to form an aminyl radical ( $\mathrm{PzN})$. The extent of branching to the $\mathrm{PzN}$ radical is of particular interest, as aminyl radicals can react with $\mathrm{NO}$ and $\mathrm{NO}_{2}$ to generate toxic nitrosamines and nitramines, respectively. ${ }^{22-29}$ On the other hand, $\alpha$-aminoalkyl radicals such as $\mathrm{PzC}$ have been shown to predominantly react with $\mathrm{O}_{2}$ to produce imines. ${ }^{30,31}$ Experimentally, $\mathrm{Pz}$ has been shown to react with ${ }^{\circ} \mathrm{OH}$ mainly via $\mathrm{C}-\mathrm{H}$ abstraction, although there is limited information on the further reaction products under atmospheric conditions. ${ }^{11,32,33}$ This 
motivated us to carry out a theoretical kinetics investigation into the $\mathrm{Pz}+{ }^{\circ} \mathrm{OH}$ reaction through multiple reaction stages, to help validate existing experimental results as well as to provide new insight into the ultimate products of atmospheric oxidation.

\section{Methods}

The G4 composite model has been used for all ab initio calculations. ${ }^{34}$ It is a multistep method, in which density functional theory (B3LYP/6-31g(2df,p)) optimized geometries are used for wavefunction theory single-point energy calculations from HF to $\operatorname{CCSD}(\mathrm{T})$ paired with basis sets of incrementally decreasing size, along with added empirical corrections (using unrestricted wavefunctions for open shell species). These single-point energy steps allow for efficient approximation of the CCSD(T) energy with a complete basis set. The B3LYP method allows for computationally efficient geometry optimizations and frequency calculations, although it introduces errors on the order of $0.06 \AA^{35}$ for critical transition state parameters. As a result the $\mathrm{G} 4$ method accurately predicts barrier heights at reasonable computational cost, with mean unsigned error in barrier heights expected to be less than $1 \mathrm{kcal} / \mathrm{mol} .{ }^{36}$ Frequency calculations confirmed all minima to have zero imaginary frequencies and all transition states to have one imaginary frequency, with intrinsic reaction coordinate calculations used to confirm transition state connectivity. Where multiple conformations are available we refer to the lowest energy structure. Gaussian 16 was used for all reported electronic structure calculations. ${ }^{37}$ Coordinates of all the wells and transition states are included in Supporting Information.

The MultiWell Program Suite (2017) was employed for statistical reaction rate simulations, ${ }^{38}$ on the basis of B3LYP/6-31g(2df,p) theory moments of inertia, vibrational frequencies, and G4 theory energies. RRKM theory is used to calculate microcanonical rate coefficients, $k(E)$. In the sums and densities of state calculations, harmonic oscillators are used to describe the internal degrees of freedom and an active 1D K-rotor and inactive 2D J-rotor are used to treat external degrees of freedom. Barrierless association reactions are described using the restricted Gorin model, ${ }^{39}$ where the rate of complex formation is estimated as the dipole-quadrupole capture rate, $k_{\text {cap }}{ }^{40}$ The equation used here is $k_{\text {cap }}=C \mu^{-0.5}|d Q|^{1 / 2}$, where $\mu$ is reduced mass, and $d$ and $Q$ are the respective dipole and quadrupole moments (all in atomic units). The constant $C$ has a value of 4.49 when all variables are in atomic units, and arises from application of $\mu$ JVTST on the long-range dipole - quadrupole potential. ${ }^{40,41}$ All parameters used in capture rate calculation are included in Supporting Information Table S1. The capture rate of $\mathrm{Pz}$ and ${ }^{\circ} \mathrm{OH}$ is estimated to be $2.61 \times 10^{-10} \mathrm{~cm}^{3}$ molecule $\mathrm{e}^{-1} \mathrm{~s}^{-1}$, whereas the capture rate of $\mathrm{PzC}$ and $\mathrm{O}_{2}$ is significantly lower at $3.35 \times 10^{-11} \mathrm{~cm}^{3}$ molecule $^{-1} \mathrm{~s}^{-1}$, largely due to the small quadrupole moment of $\mathrm{O}_{2}$. Product yields are obtained from time-dependent energy grained master equation simulations. The MultiWell stochastic master equation solver simulations reaction probabilities over many trials, employing a hybrid master equation with an energy grained regime followed by a continuum regime. The energy grained master equation comprised 2000 grains with size of $10 \mathrm{~cm}^{-1}$, which was then extended from $20,000 \mathrm{~cm}^{-1}$ up to $150,000 \mathrm{~cm}^{-1}$ for the continuum component (well above any barriers or excitation energies). Each stochastic simulation featured 10 million trials and sufficient collisions to reach steady-state. The Lennard-Jones model is used to describe the collision of wells with the bath gas, $\mathrm{N}_{2}$. Additivity calculations were used to estimate the Lennard-Jones parameters, with $\sigma[\AA]=1.45\left(\sum V_{i}\right)^{1 / 3}$ and $\varepsilon / k[\mathrm{~K}]=1.21 T_{b}$, where $V_{i}$ are the additive volume increments and $T_{\mathrm{b}}$ is the boiling point $(\mathrm{K})$ estimated by Joback method. For the $\mathrm{Pz}-$ 
$\mathrm{OH}$ adducts, Lennard-Jones parameters $\sigma$ and $\varepsilon / k_{b}$ are calculated as $6.2 \AA$ and $584 \mathrm{~K}$. For $\mathrm{PzC}-\mathrm{O}_{2}$ adducts, Lennard-Jones parameters $\sigma$ and $\varepsilon / k_{b}$ are $6.04 \AA$ and $524.6 \mathrm{~K}$. The average energy in deactivating collisions, $\Delta E_{\text {down }}$, is set as $100 \mathrm{~cm}^{-1}$ in the $\mathrm{Pz}+{ }^{-} \mathrm{OH}$ reaction and $100 \pm 50 \mathrm{~cm}^{-1}$ for $\mathrm{PzC}+$ $\mathrm{O}_{2}$.

\section{Results and Discussion}

The ${ }^{\circ} \mathrm{OH}$ radical can abstract $\mathrm{H}$ from either a $\mathrm{N}$ site on $\mathrm{Pz}$, to form a $\mathrm{N}$ atom centred aminyl radical $(\mathrm{PzN})+\mathrm{H}_{2} \mathrm{O}$, or a $\mathrm{C}$ site on $\mathrm{Pz}$, to form a $\mathrm{C}$ atom centred alkyl radical $(\mathrm{PzC})+\mathrm{H}_{2} \mathrm{O}$. A theoretical energy diagram of the $\mathrm{Pz}+{ }^{\circ} \mathrm{OH}$ reaction is depicted in Figure 1 . The optimised geometries of the transition states and wells in the $\mathrm{H}$ abstraction are shown in Figure $\mathbf{2}$.

The initial step begins with the approach of ${ }^{\circ} \mathrm{OH}$ radical to $\mathrm{Pz}$, resulting in barrierless and exothermic formation of pre-reaction adduct 1 by $8.1 \mathrm{kcal} \mathrm{mol}^{-1}$. Pre-reactant complex 1 can interconvert to 2 (4.9 $\mathrm{kcal} \mathrm{mol}^{-1}$ below the entrance) via TS3, which sits at close to the energy of $\mathbf{2}$. Note that the $0 \mathrm{~K}$ enthalpy of TS3 is $0.7 \mathrm{kcal} \mathrm{mol}^{-1}$ below 2 ; this indicates a small reaction barrier ${ }^{42}$ that is close to the zero point energies, and may also be an artefact of the multilevel calculations. This process predominantly involves rotation of the $\mathrm{OH}$ group; the $\mathrm{H}-\mathrm{O}-\mathrm{N}-\mathrm{H}$ dihedral changes from almost $0^{\circ}$ in 1 to about $112^{\circ}$ in $\mathbf{2}$, and is $-28^{\circ}$ in TS3. From $\mathbf{1}$ the $\mathrm{C}-\mathrm{H}$ bond will break via TS1 which sits $1.4 \mathrm{kcal} \mathrm{mol}^{-1}$ above 1 (6.7 kcal mol ${ }^{-1}$ below the reactants). From 2, the $\mathrm{N}-\mathrm{H}$ bond will break via transition state TS2 which is $3.3 \mathrm{kcal} \mathrm{mol}^{-1}$ above 2 (1.6 kcal mol${ }^{-1}$ below $\left.\mathrm{Pz}+{ }^{\circ} \mathrm{OH}\right)$. After $\mathrm{H}$ abstraction, TS1 leads to the alky radical $(\mathrm{PzC})$ and $\mathrm{H}_{2} \mathrm{O}$, whereas TS2 goes to the aminyl radical $(\mathrm{PzN})$ and $\mathrm{H}_{2} \mathrm{O}$ in a marginally less exothermic process. According to the potential energy diagram developed here we would expect $\mathrm{PzC}$ to be the dominant reaction product, due to both the lower abstraction barrier and the ability for the two pre-reaction complexes to readily interconvert.

In order to quantify the $\mathrm{Pz}+{ }^{\circ} \mathrm{OH}$ reaction kinetics, master equation modelling has been carried out from $300 \mathrm{~K}$ to $500 \mathrm{~K}$ at $1 \mathrm{~atm} \mathrm{~N}$. As is shown in Figure 3, the calculated rate coefficient at $300 \mathrm{~K}$ matches the experimental result of Onel et al. ${ }^{33}$ Additionally, the negative activation energy is captured reasonably well. ${ }^{33}$ At $300 \mathrm{~K}, \mathrm{C}-\mathrm{H}$ and $\mathrm{N}-\mathrm{H}$ abstraction rate coefficients are estimated to be $k_{\text {Cabst }}=k_{\text {cap }} \times y_{\mathrm{C}-\mathrm{H}}=2.38 \times 10^{-10} \mathrm{~cm}^{3}$ molecule $^{-1} \mathrm{~s}^{-1}$ and $k_{\mathrm{N} a b s t}=k_{\text {cap }} \times y_{\mathrm{N}-\mathrm{H}}=2.66 \times 10^{-12} \mathrm{~cm}^{3}$ molecule $\mathrm{e}^{-1} \mathrm{~s}^{-1}$ respectively, where $y_{\mathrm{C}-\mathrm{H}}$ is the yield of $\mathrm{C}-\mathrm{H}$ abstraction products and $y_{\mathrm{N}-\mathrm{H}}$ is the yield of $\mathrm{N}-\mathrm{H}$ abstraction products. Predicted branching to $\mathrm{C}-\mathrm{H}$ abstraction is $k_{\mathrm{Cabst}} /\left(k_{\mathrm{C} a b s t}+k_{\mathrm{Nabst}}\right)$ $\approx 99 \%$, confirming this as the major reaction channel. As temperature increases from 300 to $500 \mathrm{~K}$, the branching ratio of $\mathrm{C}-\mathrm{H}$ abstraction remains as the major reaction channel and slightly decreases from $99 \%$ to $94 \%$. Yields, abstraction rate coefficients, and branching ratios of both channels at 300 to $500 \mathrm{~K}$ are listed in Supporting information (Table S2). Thus, subsequent reactions between PzN and $\mathrm{NO}$ or $\mathrm{NO}_{2}$ which may produce carcinogenic nitrosamines and nitramines are predicted to be minor in the atmospheric oxidation of piperazine initiated by ${ }^{\circ} \mathrm{OH}$, although due to their potentially acute toxicity they may still need to be included in atmospheric chemical mechanisms. 


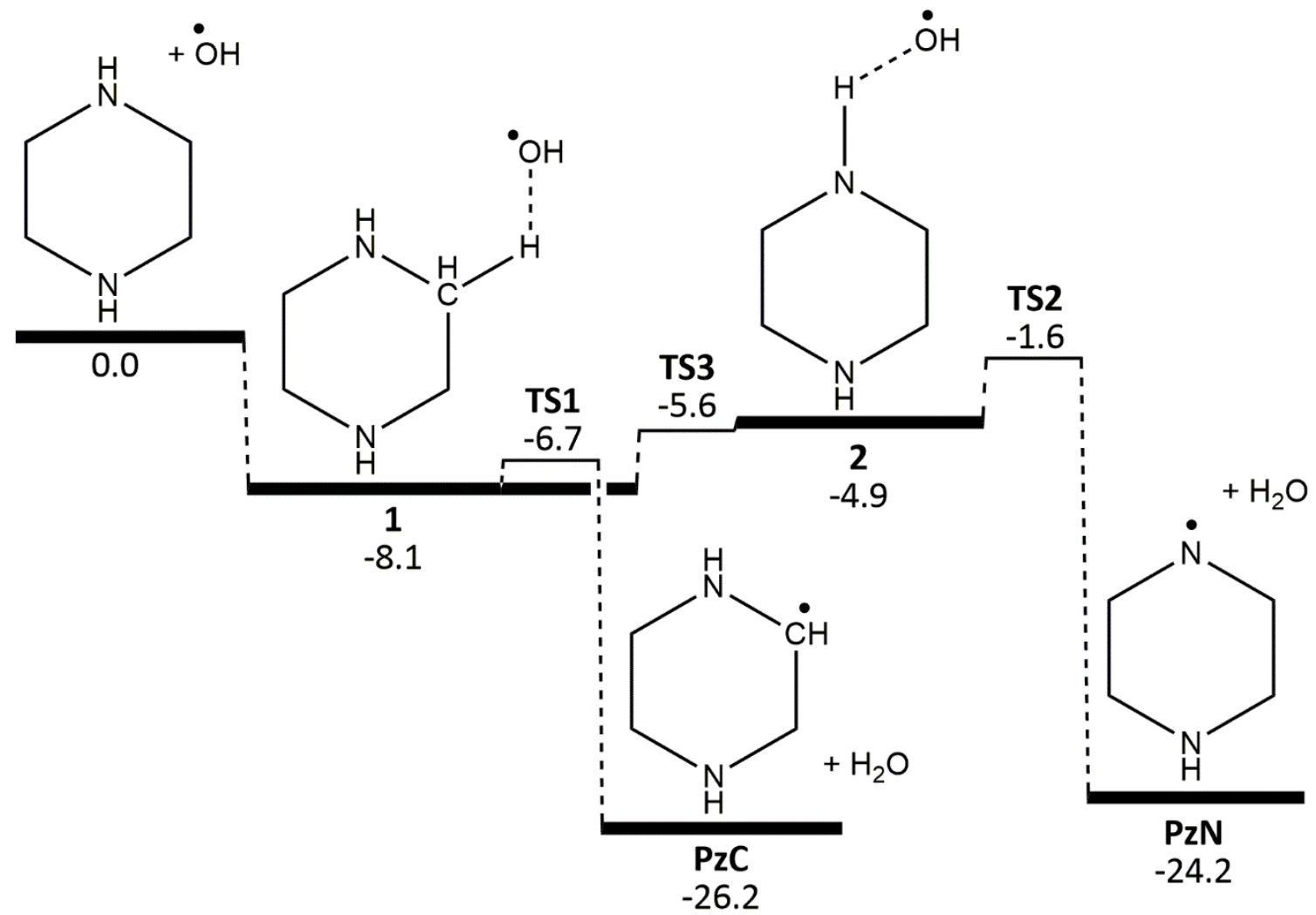

Figure 1. Potential energy diagram for the piperazine $+{ }^{\bullet} \mathrm{OH}$ reaction. Relative energies are $0 \mathrm{~K}$ enthalpies in the units of $\mathrm{kcal} \mathrm{mol}^{-1}$, at the $\mathrm{G} 4$ level of theory.

TS1

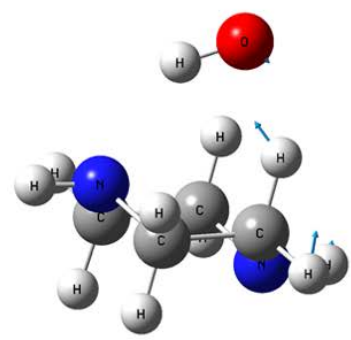

TS2

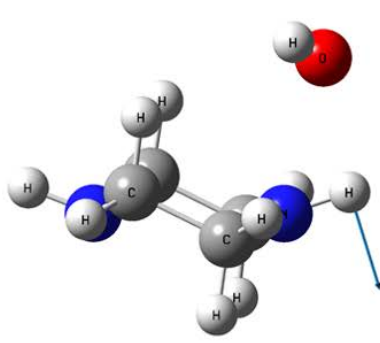

TS3
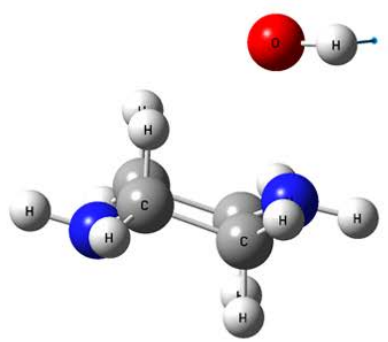

1

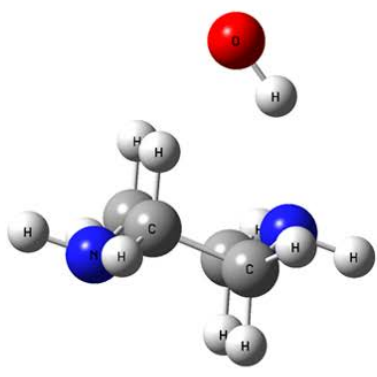

2

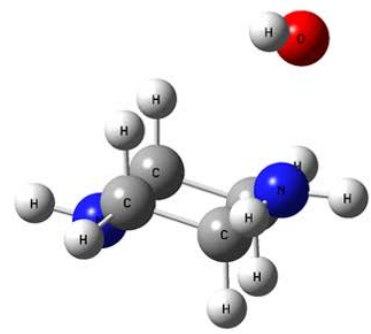

Figure 2. Optimized structures of the wells and transition states of $\mathrm{Pz}+{ }^{\circ} \mathrm{OH}$ reaction at $\mathrm{G} 4$ level of theory. For the transition states, displacement vectors of the imaginary frequency are included. 


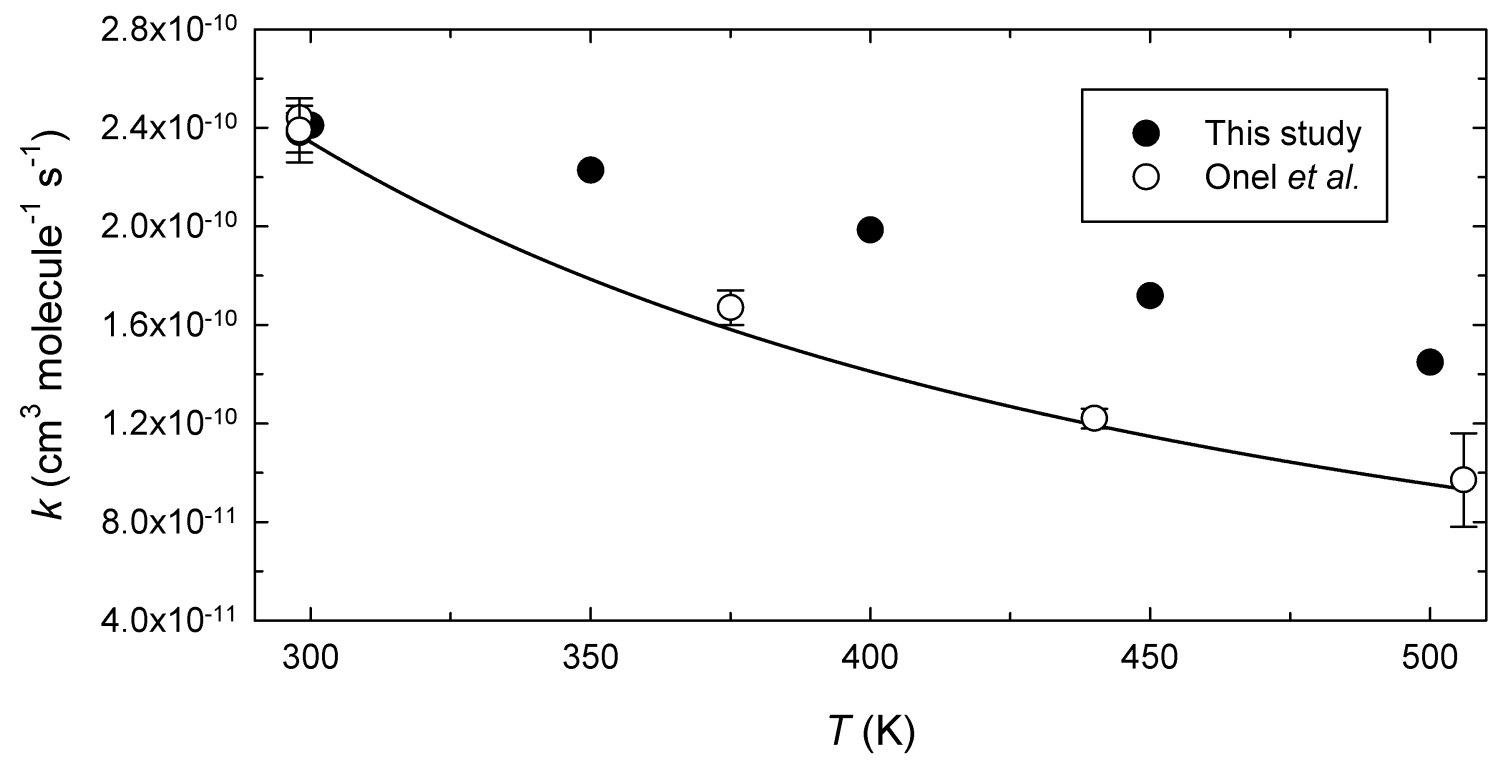

Figure 3. Total rate coefficient $(k)$ from calculations and experiments as a function of temperature $(T)$ in the $\mathrm{Pz}+{ }^{\bullet} \mathrm{OH}$ reaction.

Once formed, the $\mathrm{PzC}$ radical will rapidly react with $\mathrm{O}_{2}$ in the atmosphere. The energy diagram for the reaction of $\mathrm{PzC}+\mathrm{O}_{2}$ is shown in Figure 4. Energies of all the transition states, intermediates and products are below the reactants. The optimised structures of the transition states and wells in the mechanisms are illustrated in Figure 5. Firstly, the alkyl radical $(\mathrm{PzC})$ combines with molecular $\mathrm{O}_{2}$ to form the peroxyl radical $\left(\mathrm{RO}_{2}{ }^{\circ}\right)$ intermediate 3 , releasing $35 \mathrm{kcal} \mathrm{mol}^{-1}$ in energy. Relaxed potential energy scans confirmed this step to be barrierless. From here, $\mathbf{3}$ can undergo $\mathrm{HO}_{2}{ }^{\bullet}$ elimination via a five-member ring like transition state, TS4, which is $16.4 \mathrm{kcal} \mathrm{mol}^{-1}$ below the reactant and $19 \mathrm{kcal}^{\mathrm{mol}}{ }^{-}$ ${ }^{1}$ above the peroxyl radical 3. Following $\mathrm{HO}_{2}{ }^{\bullet}$ elimination there is the formation of a weak postreactant adduct 4, which can dissociate to the cyclic imine 1,2,3,6-tetrahydropyrazin and $\mathrm{HO}_{2}{ }^{\circ}$, whose energies are $14.4 \mathrm{kcal} \mathrm{mol}^{-1}$ below the reactants. We preliminarily considered other isomerization and dissociation channels of the peroxyl radical $\mathbf{3}$ (see Figure S1 and Table S3 in Supporting Information) although they all have substantial barriers and were subsequently excluded. 


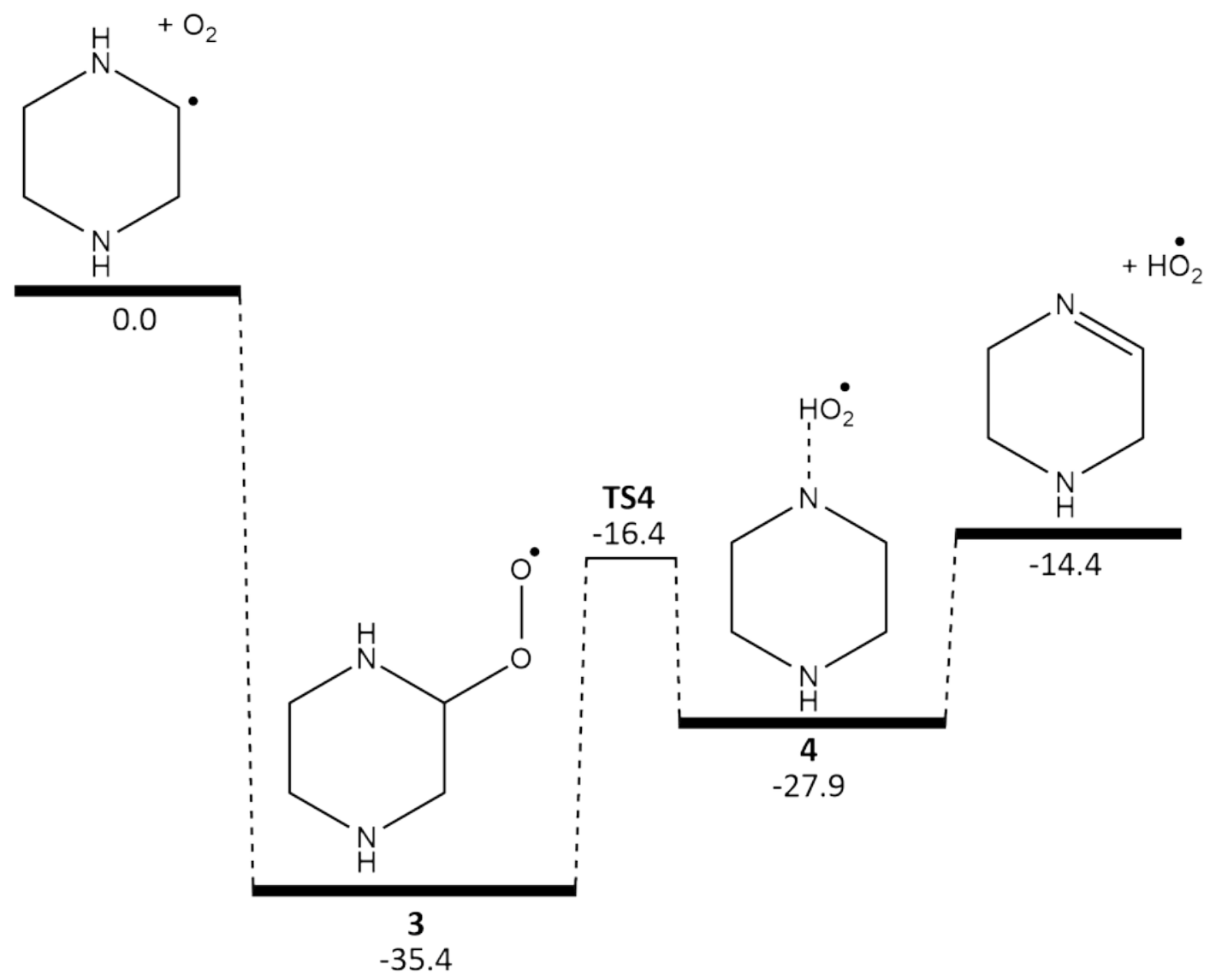

Figure 4. Potential energy diagram for the reaction of $\mathrm{PzC}+\mathrm{O}_{2}$ generating 1,2,3,6-tetrahydropyrazin + $\mathrm{HO}_{2}{ }^{\circ}$. Relative energies are $0 \mathrm{~K}$ enthalpies in the units of $\mathrm{kcal} \mathrm{mol}^{-1}$, at the $\mathrm{G} 4$ level of theory.

TS4

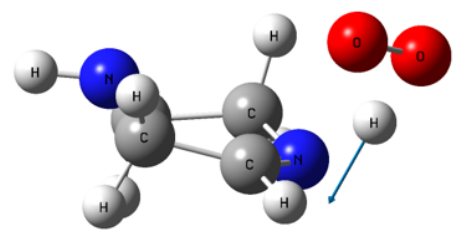

3

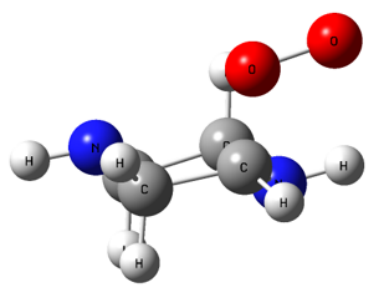

4

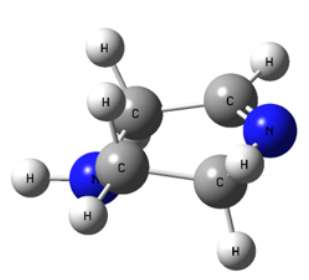

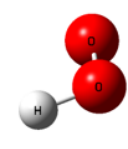

Figure 5. Optimized structures of the wells and transition states of $\mathrm{PzC}+\mathrm{O}_{2}$ reaction at the $\mathrm{G} 4$ level of theory. For the transition state, displacement vectors of the imaginary frequency are included.

It is apparent from Figure 4 that following the association of $\mathrm{PzC}$ with $\mathrm{O}_{2}$, the chemically activated peroxyl radical will have sufficient energy to dissociate to $1,2,3,6$-tetrahydropyrazin $+\mathrm{HO}_{2}{ }^{\circ}$. This process will, however, be in competition with collisional deactivation of the peroxyl radical as well as reverse dissociation to the reactants. To better understand these processes, a master equation model 
has been developed, and simulations were carried out at 14 Torr (the pressure of the Onel et al. study) and $1 \mathrm{~atm} \mathrm{~N}_{2}$. At 14 Torr, we predict no peroxyl radical stabilization, supporting the assumption of Onel et al. that $\mathrm{PzC}$ was quantitatively oxidised to $\mathrm{HO}_{2}{ }^{\circ}$ in their reactor. From the 1 atm simulations the only significant product channels predicted were for dissociation to the imine $+\mathrm{HO}_{2}{ }^{\bullet}$ plus peroxyl radical stabilization; there was negligible reverse dissociation to reactants. Although peroxyl radical stabilization becomes significant at atmospheric pressure, the predicted yields were sensitive to the collisional energy transfer model adopted. The time-evolution of peroxyl radical $\mathbf{3}$ in the $\mathrm{PzC}+\mathrm{O}_{2}$ reaction at $298 \mathrm{~K}$ and $1 \mathrm{~atm} \mathrm{~N}_{2}$ is plotted in Figure 6, for $\Delta E_{\text {down }}=100 \pm 50 \mathrm{~cm}^{-1}$. At $100 \mathrm{~cm}^{-1}$ the steadystate peroxyl radical yield is $11.3 \%$, increasing to $26.9 \%$ at $150 \mathrm{~cm}^{-1}$ and dropping to effectively zero at $50 \mathrm{~cm}^{-1}$.

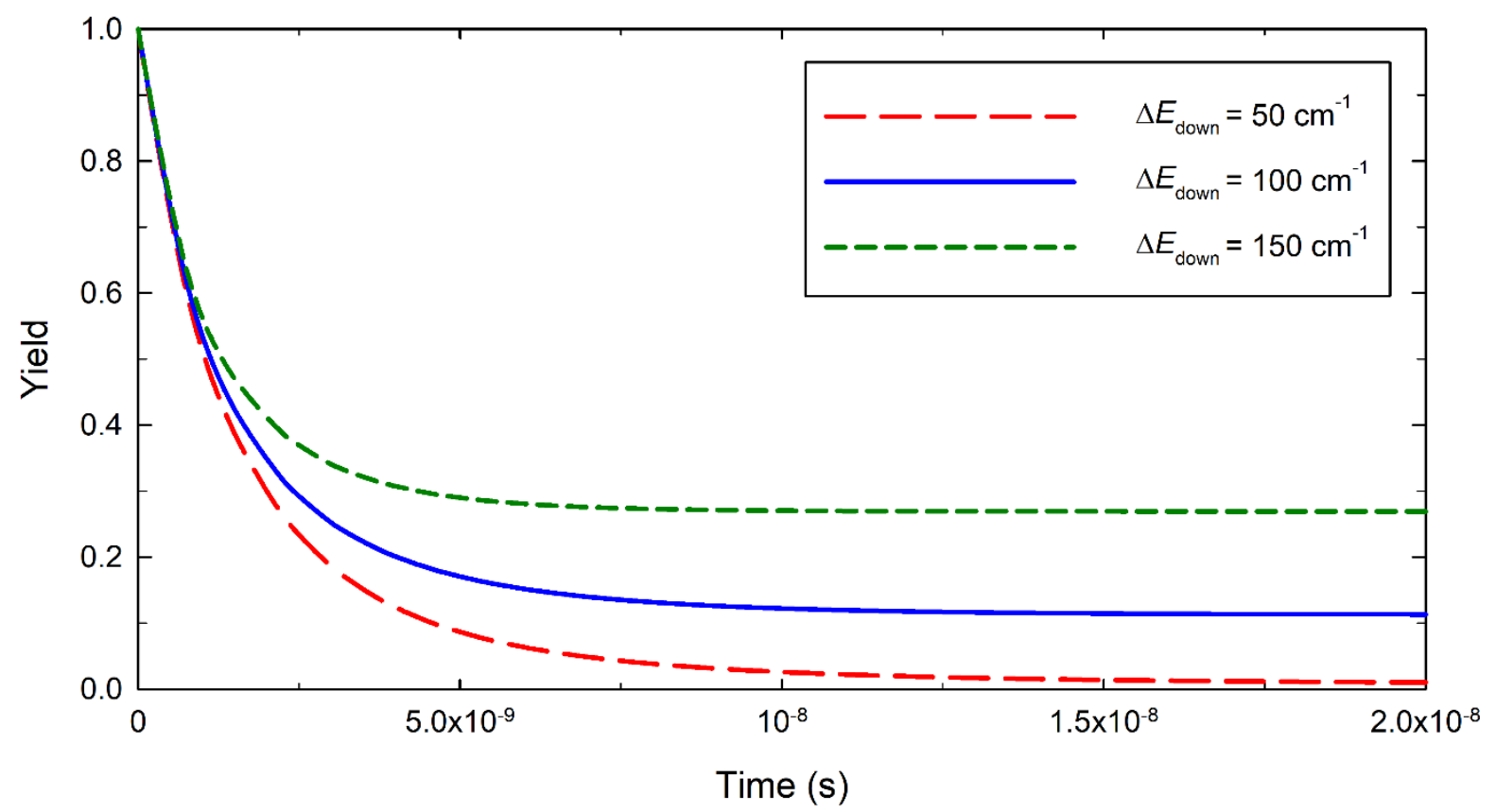

Figure 6. Predicted $\mathrm{RO}_{2}{ }^{\bullet}$ peroxyl radical yields $v s$. time from master equation simulations at $298 \mathrm{~K}$ and 1 atm $\mathrm{N}_{2}$.

Although not the major product in the atmospheric degradation of $\mathrm{Pz}$, we predict that the peroxyl radical 3 will be formed to some extent, yet its further reaction pathways have to date been unexplored. In polluted environments the dominant fate will be reaction with NO to produce an alkoxyl radical (RO'), 5, as shown in Eqn (1). The energy release of this process is calculated as 10.0 $\mathrm{kcal}^{\mathrm{mol}}{ }^{-1}$, which will provide the RO $\mathrm{O}^{\bullet}$ radical with some excess vibrational energy over that of a thermalized population.

$$
\mathrm{RO}_{2}^{\bullet}+\mathrm{NO} \rightarrow \mathrm{RO}^{\bullet}+\mathrm{NO}_{2}
$$

Following the formation of $\mathrm{RO}^{\circ}$, there is competition between the bimolecular reaction $\mathrm{RO}^{\circ}+\mathrm{O}_{2}$ and unimolecular $\mathrm{RO}^{*}$ chemistry. The energy diagram for the $\mathrm{RO}^{*}+\mathrm{O}_{2}$ reaction is depicted in the Supporting Information (Figure S2); this reaction produces a cyclic amide via a transition state which is $3.1 \mathrm{kcal} \mathrm{mol}^{-1}$ above the entrance channel. A diagram illustrating the main isomerisation and decomposition pathways of the alkoxyl radical RO ${ }^{*}$ are shown in Figure 7. The alkoxyl radical can break 
the $\mathrm{C}-\mathrm{N}$ bond and form a N-centred radical $\mathrm{HCOCH}_{2} \mathrm{NHCH}_{2} \mathrm{CH}_{2} \mathrm{NH}^{-}$with a barrier of $14.3 \mathrm{kcal} \mathrm{mol}^{-1}$. Direct $\mathrm{C}-\mathrm{H}$ beta-scission leading to $\mathrm{H}$ loss, forming a cyclic amide, proceeds with a barrier of $8.9 \mathrm{kcal}$ $\mathrm{mol}^{-1}$. Intramolecular $\mathrm{H}$-shifts from both neighbouring $\mathrm{N}-\mathrm{H}$ and $\mathrm{C}-\mathrm{H}$ groups were also investigated although the barriers were prohibitively large (20.8 and $25 \mathrm{kcal} \mathrm{mol}^{-1}$ respectively) and they are not shown. The alkoxyl radical can also break the $\mathrm{C}-\mathrm{C}$ bond via a multistep process (TS7 - TS9) with a barrier lower than both the $\mathrm{H}$ loss and $\mathrm{C}-\mathrm{N}$ bond breaking reactions. Firstly, the directions of the $\mathrm{H}-$ $\mathrm{N}$ bonds located at the meta and ortho $\mathrm{N}$ atoms sequentially change from equatorial to axial. Then $\mathrm{C}-\mathrm{C}$ bond cleavage forms a ring-opened structure $\mathrm{HCONHCH}_{2} \mathrm{CH}_{2} \mathrm{NHCH}_{2} \cdot$ via a near-barrierless process. Subsequent $\mathrm{H}$ shift reactions of $\mathrm{HCONHCH}_{2} \mathrm{CH}_{2} \mathrm{NHCH}_{2}{ }^{\circ}$ have also been explored, although all energies are significantly above the entrance channel (see Supporting Information Figure S3). Accordingly, the main alkoxyl radical product is expected to be the open chain alkyl radical $\mathrm{HCONHCH}_{2} \mathrm{CH}_{2} \mathrm{NHCH}_{2}{ }^{\circ}$, which can undergo a second $\mathrm{O}_{2}$ addition mechanism.

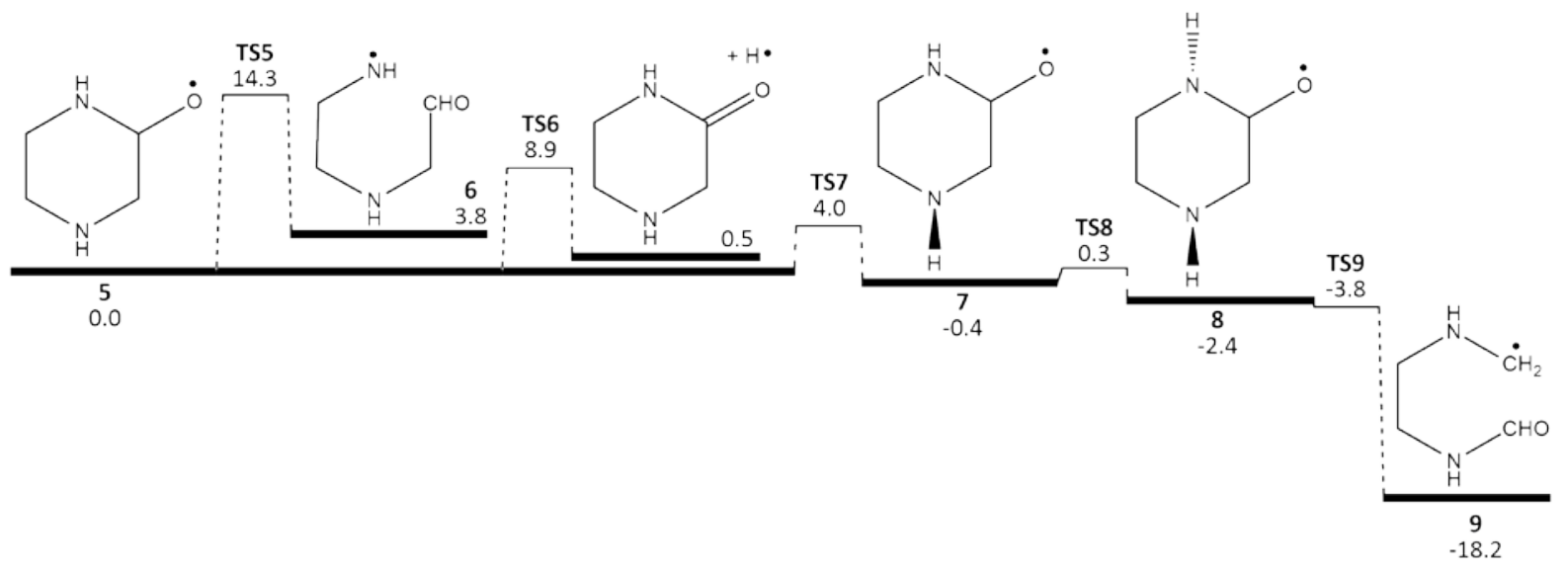

Figure 7. Potential energy diagram for $\mathrm{PzC}$ alkoxyl radical isomerisation. Relative energies are $0 \mathrm{~K}$ enthalpies in the units of $\mathrm{kcal} \mathrm{mol}^{-1}$, at the $\mathrm{G} 4$ level of theory.

Similar to the alkyl radical $\mathrm{PzC}, \mathrm{HCONHCH}{ }_{2} \mathrm{CH}_{2} \mathrm{NHCH}_{2}{ }^{\circ}$ reacts with $\mathrm{O}_{2}$ to form a peroxyl radical (10), releasing $33.3 \mathrm{kcal} \mathrm{mol}^{-1}$ in energy. Subsequently, 10 can undergo $\mathrm{HO}_{2}{ }^{\circ}$ elimination via TS10, which is $19.4 \mathrm{kcal} \mathrm{mol}^{-1}$ above 10 (13.9 kcal mol${ }^{-1}$ below $\mathrm{HCONHCH}_{2} \mathrm{CH}_{2} \mathrm{NHCH}_{2}{ }^{\bullet}+\mathrm{O}_{2}$ ). After $\mathrm{HO}_{2}{ }^{\bullet}$ elimination, TS10 leads to the post-reactant complex 11 , which will dissociate to $\mathrm{CH}_{2}=\mathrm{NCH}_{2} \mathrm{CH}_{2} \mathrm{NHCHO}$ and $\mathrm{HO}_{2}{ }^{\circ}$, whose energies are $12.3 \mathrm{kcal} \mathrm{mol}^{-1}$ above well 11 and $13.7 \mathrm{kcal} \mathrm{mol}^{-1}$ below the entrance channel. The relevant energy diagram is depicted in Figure $\mathbf{8}$, and a higher-energy competing process involving formyl $\mathrm{H}$ abstraction is shown in Figure $\mathrm{S} 4$ of the Supporting Information. The $\mathrm{CH}_{2}=\mathrm{NCH}_{2} \mathrm{CH}_{2} \mathrm{NHCHO}$ product bears an amide functional group, and the further oxidation of this species may therefore lead to toxic isocyanates..$^{43-45}$

Based upon the results presented above, we predict that $\mathrm{Pz}$ will react with ${ }^{\circ} \mathrm{OH}$ in the troposphere to almost exclusively produce the carbon-centred radical $\mathrm{PzC}$. Subsequent reaction with $\mathrm{O}_{2}$ then leads predominantly to the imine 1,2,3,6-tetrahydropyrazin $\left(+\mathrm{HO}_{2}{ }^{\circ}\right)$, but with a stabilised peroxyl radical yield of about $10 \%$. The corresponding alkoxyl radical can undergo ring opening followed by second $\mathrm{O}_{2}$ addition to produce an open-chain imine, $\mathrm{CH}_{2}=\mathrm{NCH}_{2} \mathrm{CH}_{2} \mathrm{NHCHO}$. These findings are summarized in Figure 9. Further to this work the fate of the imines may need to be considered in order to completely appreciate the air quality impacts of piperazine. 


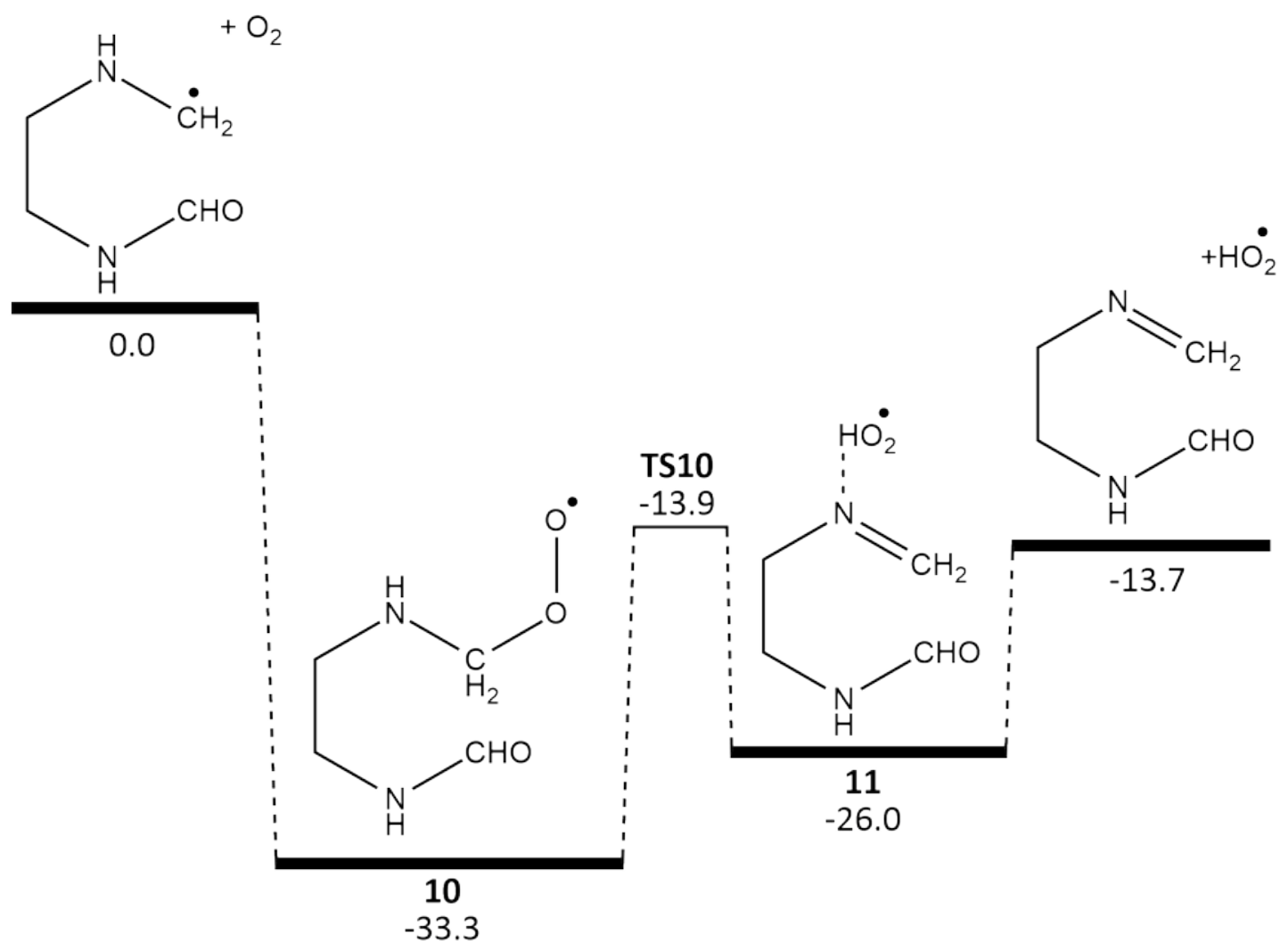

Figure 8. Potential energy diagram for $\mathrm{HCONHCH}_{2} \mathrm{CH}_{2} \mathrm{NHCH}_{2}{ }^{\bullet}+\mathrm{O}_{2}$ reaction. Relative energies are $0 \mathrm{~K}$ enthalpies in the units of $\mathrm{kcal} \mathrm{mol}^{-1}$, at the $\mathrm{G} 4$ level of theory.

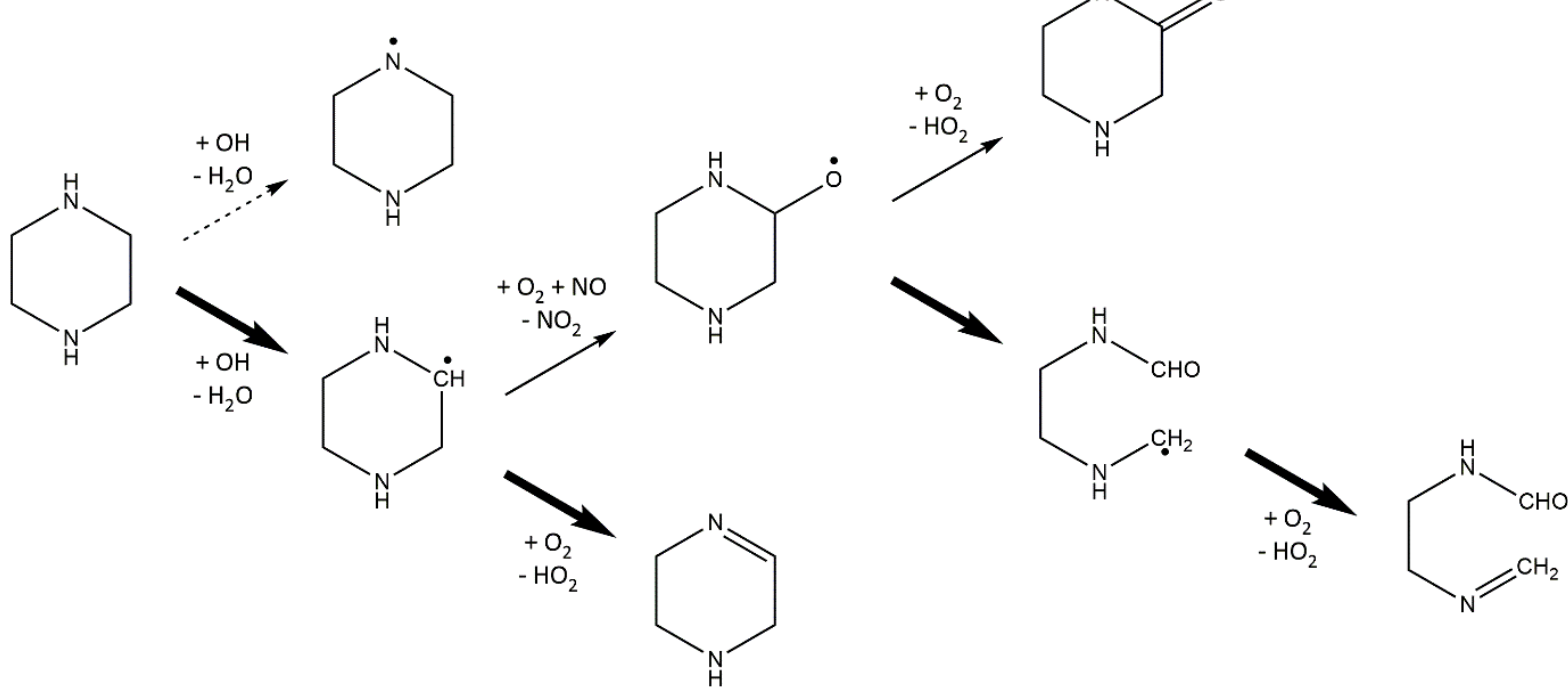

Figure 9. Proposed atmospheric reaction scheme for the ${ }^{\circ} \mathrm{OH}$ radical initiated oxidation of piperazine.

\section{Summary and Conclusions}


In this work the ${ }^{\circ} \mathrm{OH}$ initiated atmospheric oxidation of $\mathrm{Pz}$ has been studied. $\mathrm{H}$ abstraction from $\mathrm{C}-\mathrm{H}$ sites is found to have a lower barrier than $\mathrm{N}-\mathrm{H}$ sites, and master equation modelling confirms that $\mathrm{H}$ abstraction happens predominantly on $\mathrm{C}-\mathrm{H}$ sites. Predicted rate coefficients for the $\mathrm{Pz}+{ }^{\circ} \mathrm{OH}$ reaction are consistent with experiment. Reaction of the alkyl piperazine radical $\mathrm{PzC}$ with $\mathrm{O}_{2}$ is is also investigated, with the main product predicted to be a cyclic imine produced via a $\mathrm{HO}_{2}{ }^{\bullet}$ elimination process, with minor yield of the stabilized peroxyl radical. The alkoxyl radical formed in the reaction of $\mathrm{RO}_{2}{ }^{-}+\mathrm{NO}$ can subsequently isomerize and react with a second $\mathrm{O}_{2}$ to produce $\mathrm{CH}_{2}=\mathrm{NCH}_{2} \mathrm{CH}_{2} \mathrm{NHCHO}$ and $\mathrm{HO}_{2}{ }^{\circ}$.

\section{Supporting Information Available:}

Potential energy diagrams for the $\mathrm{PzC}+\mathrm{O}_{2}$ reaction followed by $\mathrm{H}$ shift from the meta- $\mathrm{C}, \mathrm{RO}^{\bullet}+\mathrm{O}_{2}$ reaction, $\mathrm{HCONHCH}_{2} \mathrm{CH}_{2} \mathrm{NHCH}_{2}{ }^{\circ}$ isomerisation and formyl $\mathrm{H}$ abstraction in the $\mathrm{HCONHCH}_{2} \mathrm{CH}_{2} \mathrm{NHCH}_{2}{ }^{\circ}$ $+\mathrm{O}_{2}$ reaction, parameters used in capture rates calculation and calculated yields, rate coefficients, branching ratios and coordinates of the wells and transition states.

\section{Acknowledgements}

This work was supported by the Australian Research Council through the Future Fellowships program.

\section{References}

1. Haszeldine, R. S., Carbon Capture and Storage: How Green Can Black Be? Science 2009, 325 (5948), 1647-1652.

2. Bui, M.; Adjiman, C. S.; Bardow, A.; Anthony, E. J.; Boston, A.; Brown, S.; Fennell, P. S.; Fuss, S.; Galindo, A.; Hackett, L. A., Carbon capture and storage (CCS): the way forward. Energy \& Environmental Science 2018, 11 (5), 1062-1176.

3. Wall, T. F., Combustion processes for carbon capture. Proceedings of the combustion institute 2007, 31 (1), 31-47.

4. Cuéllar-Franca, R. M.; Azapagic, A., Carbon capture, storage and utilisation technologies: A critical analysis and comparison of their life cycle environmental impacts. Journal of $\mathrm{CO} 2$ utilization 2015, 9, 82-102.

5. Xie, H.-B.; Johnson, J. K.; Perry, R. J.; Genovese, S.; Wood, B. R., A computational study of the heats of reaction of substituted monoethanolamine with $\mathrm{CO} 2$. The Journal of Physical Chemistry A 2010, 115 (3), 342-350.

6. Liu, Y.; Zhang, L.; Watanasiri, S., Representing vapor- liquid equilibrium for an aqueous MEA- $\mathrm{CO} 2$ system using the electrolyte nonrandom-two-liquid model. Industrial \& engineering chemistry research 1999, 38 (5), 2080-2090.

7. Thee, H.; Suryaputradinata, Y. A.; Mumford, K. A.; Smith, K. H.; da Silva, G.; Kentish, S. E.; Stevens, G. W., A kinetic and process modeling study of $\mathrm{CO} 2$ capture with MEA-promoted potassium carbonate solutions. Chemical engineering journal 2012, 210, 271-279.

8. Gray, M.; Soong, Y.; Champagne, K.; Baltrus, J.; Stevens Jr, R.; Toochinda, P.; Chuang, S., $\mathrm{CO} 2$ capture by amine-enriched fly ash carbon sorbents. Separation and Purification Technology 2004, 35 (1), 31-36. 
9. Lepaumier, H.; Picq, D.; Carrette, P.-L., New amines for $\mathrm{CO} 2$ capture. II. Oxidative degradation mechanisms. Industrial \& Engineering Chemistry Research 2009, 48 (20), 9068-9075.

10. Pires, J.; Martins, F.; Alvim-Ferraz, M.; Simões, M., Recent developments on carbon capture and storage: an overview. Chemical engineering research and design 2011, 89 (9), 1446-1460.

11. White, S.; Angove, D.; Azzi, M.; Tibbett, A.; Campbell, I.; Patterson, M., An experimental investigation into the atmospheric degradation of piperazine. Atmospheric Environment 2015, 108, 133-139.

12. Knudsen, S.; Karl, M.; Randall, S., Amine emissions to air during carbon capture. Norwegian Institute for Air Research 2009.

13. Freeman, S. A.; Dugas, R.; Van Wagener, D. H.; Nguyen, T.; Rochelle, G. T., Carbon dioxide capture with concentrated, aqueous piperazine. International Journal of Greenhouse Gas Control 2010, 4 (2), 119-124.

14. Ma, F.; Xie, H.-B.; Elm, J.; Shen, J.; Chen, J.; Vehkamaki, H., Piperazine enhancing sulfuric acid-based new particle formation: implications for the atmospheric fate of piperazine.

Environmental science \& technology 2019, 53 (15), 8785-8795.

15. Rochelle, G.; Chen, E.; Freeman, S.; Van Wagener, D.; Xu, Q.; Voice, A., Aqueous piperazine as the new standard for $\mathrm{CO} 2$ capture technology. Chemical engineering journal 2011, 171 (3), 725733.

16. Nielsen, C. J.; Herrmann, H.; Weller, C., Atmospheric chemistry and environmental impact of the use of amines in carbon capture and storage (CCS). Chemical Society Reviews 2012, 41 (19), 6684-6704.

17. Ge, X.; Wexler, A. S.; Clegg, S. L., Atmospheric amines-Part I. A review. Atmospheric environment 2011, 45 (3), 524-546.

18. Gouedard, C.; Picq, D.; Launay, F.; Carrette, P.-L., Amine degradation in CO2 capture. I. A review. International Journal of Greenhouse Gas Control 2012, 10, 244-270.

19. Zhu, L.; Schade, G. W.; Nielsen, C. J., Real-time monitoring of emissions from monoethanolamine-based industrial scale carbon capture facilities. Environmental science \& technology 2013, 47 (24), 14306-14314.

20. Le, X. T.; Mai, T. V.-T.; Duong, M. v.; Huynh, L. K., Kinetics of hydrogen abstraction from desflurane by $\mathrm{OH}$ and $\mathrm{Cl}$ radicals-A theoretical study. Chemical Physics Letters 2019, 728, 142-147.

21. Anglada, J. M.; Crehuet, R.; Martins-Costa, M.; Francisco, J. S.; Ruiz-López, M., The atmospheric oxidation of $\mathrm{CH} 3 \mathrm{OOH}$ by the $\mathrm{OH}$ radical: The effect of water vapor. Physical Chemistry Chemical Physics 2017, 19 (19), 12331-12342.

22. Låg, M.; Lindeman, B.; Instanes, C.; Brunborg, G.; Schwarze, P., Health effects of amines and derivatives associated with CO2 capture. IARC Sci Publ 1984, 57, 3-22.

23. Onel, L.; Thonger, L.; Blitz, M.; Seakins, P.; Bunkan, A.; Solimannejad, M.; Nielsen, C., Gasphase reactions of $\mathrm{OH}$ with methyl amines in the presence or absence of molecular oxygen. An experimental and theoretical study. The Journal of Physical Chemistry A 2013, 117 (41), 1073610745.

24. Dai, N.; Shah, A. D.; Hu, L.; Plewa, M. J.; McKague, B.; Mitch, W. A., Measurement of nitrosamine and nitramine formation from NOx reactions with amines during amine-based carbon dioxide capture for postcombustion carbon sequestration. Environmental science \& technology 2012, 46 (17), 9793-9801.

25. Ma, F.; Ding, Z.; Elm, J.; Xie, H.-B.; Yu, Q.; Liu, C.; Li, C.; Fu, Z.; Zhang, L.; Chen, J., Atmospheric Oxidation of Piperazine Initiated by $\mathrm{Cl}$ : Unexpected High Nitrosamine Yield.

Environmental science \& technology 2018, 52 (17), 9801-9809.

26. Onel, L.; Blitz, M.; Dryden, M.; Thonger, L.; Seakins, P., Branching ratios in reactions of $\mathrm{OH}$ radicals with methylamine, dimethylamine, and ethylamine. Environmental science \& technology 2014, 48 (16), 9935-9942. 
27. Gao, H.; Wang, M.; Jin, T.; Shi, J.; Yao, X.; Jin, N., Direct dynamics study on hydrogen abstraction reaction of morpholine with hydroxyl radical. Theoretical Chemistry Accounts 2015, 134 (8), 96.

28. Goldman, M. J.; Fine, N. A.; Rochelle, G. T., Kinetics of N-nitrosopiperazine formation from nitrite and piperazine in $\mathrm{CO} 2$ capture. Environmental science \& technology 2013, 47 (7), 3528-3534. 29. Nicovich, J. M.; Mazumder, S.; Laine, P. L.; Wine, P. H.; Tang, Y.; Bunkan, A. J.; Nielsen, C. J., An experimental and theoretical study of the gas phase kinetics of atomic chlorine reactions with $\mathrm{CH} 3 \mathrm{NH}$ 2,(CH 3$) 2 \mathrm{NH}$, and (CH 3) 3 N. Physical Chemistry Chemical Physics 2015, 17 (2), 911-917. 30. da Silva, G.; Kirk, B. B.; Lloyd, C.; Trevitt, A. J.; Blanksby, S. J., Concerted HO2 elimination from $\alpha$-aminoalkylperoxyl free radicals: Experimental and theoretical evidence from the gas-phase $\mathrm{NH} 2 \cdot \mathrm{CHCO} 2-+\mathrm{O} 2$ reaction. The journal of physical chemistry letters 2012, 3 (7), 805-811.

31. Tang, Y.; Nielsen, C. J., A systematic theoretical study of imines formation from the atmospheric reactions of $\mathrm{RnNH} 2-\mathrm{n}$ with $\mathrm{O} 2$ and $\mathrm{NO} 2(\mathrm{R}=\mathrm{CH} 3$ and $\mathrm{CH} 3 \mathrm{CH} 2 ; \mathrm{n}=1$ and 2$)$. Atmospheric environment 2012, 55, 185-189.

32. Nielsen, C. J.; Bossi, R.; Bunkan, A. J. C.; Dithmer, L.; Glasius, M.; Hallquist, M.; Hansen, A. M. K.; Lutz, A.; Salo, K.; Maguta, M. M., Atmospheric Degradation of Amines (ADA): summary report from atmospheric chemistry studies of amines, nitrosamines, nitramines and amides. 2012.

33. Onel, L.; Dryden, M.; Blitz, M. A.; Seakins, P. W., Atmospheric oxidation of piperazine by $\mathrm{OH}$ has a low potential to form carcinogenic compounds. Environmental Science \& Technology Letters 2014, 1 (9), 367-371.

34. Curtiss, L. A.; Redfern, P. C.; Raghavachari, K., Gaussian-4 theory. The Journal of chemical physics 2007, $126(8), 084108$.

35. da Silva, G., G3X-K theory: A composite theoretical method for thermochemical kinetics. Chemical Physics Letters 2013, 558, 109-113.

36. Zheng, J.; Zhao, Y.; Truhlar, D. G., The DBH24/08 database and its use to assess electronic structure model chemistries for chemical reaction barrier heights. Journal of Chemical Theory and Computation 2009, 5 (4), 808-821.

37. Frisch, M.; Trucks, G.; Schlegel, H.; Scuseria, G.; Robb, M.; Cheeseman, J.; Scalmani, G.; Barone, V.; Petersson, G.; Nakatsuji, H., Gaussian 16. Revision A 2016, 3.

38. Barker, J.; Nguyen, T.; Stanton, J.; Aieta, C.; Ceotto, M.; Gabas, F.; Kumar, T.; Li, C.; Lohr, L.; Maranzana, A., MultiWell-2017 Software Suite. Ann Arbor, Michigan 2017.

39. Smith, G.; Golden, D., Application of RRKM theory to the reactions $\mathrm{OH}+\mathrm{NO} 2+\mathrm{N} 2 \rightarrow \mathrm{HONO} 2+$ $\mathrm{N} 2$ (1) and $\mathrm{ClO}+\mathrm{NO} 2+\mathrm{N} 2 \rightarrow \mathrm{ClONO} 2+\mathrm{N} 2$ (2); a modified gorin model transition state. International Journal of Chemical Kinetics 1978, 10 (5), 489-501.

40. Georgievskii, Y.; Klippenstein, S. J., Long-range transition state theory. The Journal of chemical physics 2005, 122 (19), 194103.

41. Greenwald, E. E.; North, S. W.; Georgievskii, Y.; Klippenstein, S. J., A two transition state model for radical- molecule reactions: A case study of the addition of $\mathrm{OH}$ to $\mathrm{C} 2 \mathrm{H} 4$. The Journal of Physical Chemistry A 2005, 109 (27), 6031-6044.

42. Feyel, S.; Döbler, J.; Höckendorf, R.; Beyer, M. K.; Sauer, J.; Schwarz, H., Activation of Methane by Oligomeric (Al2O3) $x+(x=3,4,5)$ : The Role of Oxygen - Centered Radicals in Thermal Hydrogen - Atom Abstraction. Angewandte Chemie International Edition 2008, 47 (10), 1946-1950.

43. Leslie, M. D.; Ridoli, M.; Murphy, J. G.; Borduas-Dedekind, N., Isocyanic acid (HNCO) and its fate in the atmosphere: A review. Environmental Science: Processes \& Impacts 2019, 21 (5), 793-808. 44. Borduas, N.; da Silva, G.; Murphy, J. G.; Abbatt, J. P., Experimental and theoretical understanding of the gas phase oxidation of atmospheric amides with $\mathrm{OH}$ radicals: kinetics, products, and mechanisms. The Journal of Physical Chemistry A 2014, 119 (19), 4298-4308. 45. Borduas, N.; Murphy, J. G.; Wang, C.; da Silva, G.; Abbatt, J. P., Gas phase oxidation of nicotine by $\mathrm{OH}$ radicals: Kinetics, mechanisms, and formation of HNCO. Environmental Science \& Technology Letters 2016, 3 (9), 327-331. 
TOC Graphic

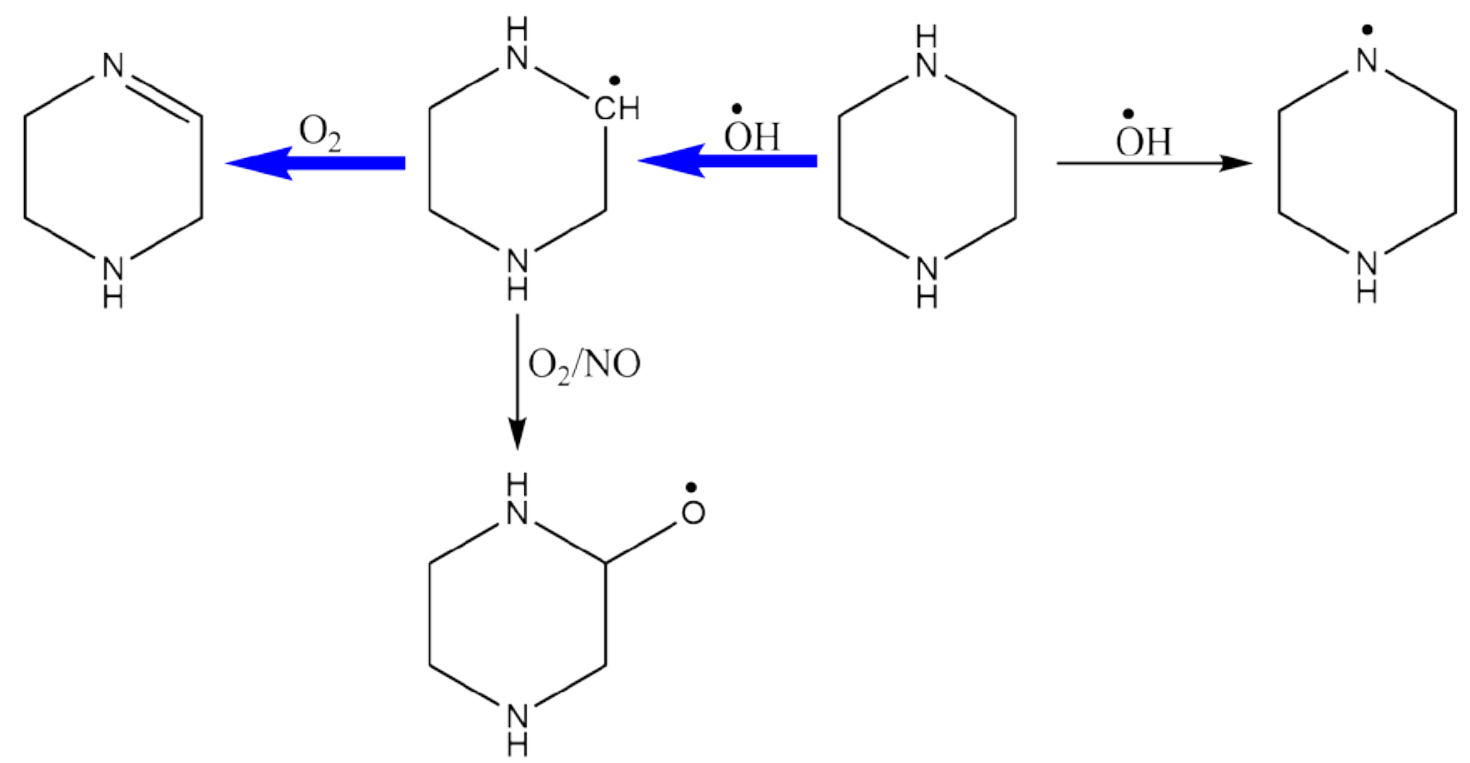

